\title{
FATIGUE DAMAGE EVALUATION OF ALLOY 718 BY INTRA-GRANULAR
}

\author{
DISTORTION ANALYSIS
}

C.Fukuoka, H.Yoshizawa, K.Morishima, S.Kihara, N.Oh-i, and II.I Iattori

Materials Technology Department

Research Institute

Ishikawajima-Harima Heavy Industries Co.,Ltd.

3-1-15 Toyosu, Koto-ku

Tokyo 135, Japan

\begin{abstract}
Absitact
Fatigue damage accumulation in Alloy 718 was evaluated by the Intra-granular Distortion (IGD) analysis which had been developed to measure creep strains of $2.25 \mathrm{Cr}-1 \mathrm{Mo}$. The IDG analysis enables to measure small distortions induced in polycrystal grains by utilizing Kikuchi patterns observed in the Transmission Electron Microscopy (TEM). Fatigue test bars fabricated from an Alloy 718 disk were cyclically deformed at two total strain ranges, $\Delta \varepsilon_{1}=0.8$ and $1.2 \%$ at $400^{\circ} \mathrm{C}$ to the failure ( $100 \%$ cumulative fatigue damage, $C D$ ), and to the damage factor of $10,30,40$, and $60 \% \mathrm{CD}$ for $\Delta \varepsilon_{1}=0.8 \%$. These specimens were observed by the optical microscopy and the TEM. The IGD analysis was also performed on the fatigued samples and an as-received sample. It is found that planar slip bands and deformation twins are increasing with fatigue accumulation, by the TEM observation. Intra-granular distortion increases with fatigue damage accumulation regardless of strain ranges. Thus it is concluded that the IGD analysis is effective to measure fatigue damage accumulation state of Alloy 718 .
\end{abstract}

Superalloys 718, 625, 706 and Various Derivatives

Edited by E. $\Lambda$. Loria

The Minerals, Metals \& Materials Society, 1997 


\section{Introduction}

Alloy 718 was developed for use at high temperature up to about $650^{\circ} \mathrm{C}$, and is used extensively in the aerospace, nuclear, and gas turbine industrics becausc of its good material properties, such as high strength, high ductility, and good low cycle fatigue / corrosion resistance ${ }^{1)}$. Strengthening mechanisms and deformation modes have been fairly well established $d^{1-4)}$.

The major intermetallic precipitates in Alloy 718 are gamma prime $\left(\gamma^{\prime}\right)$, gamma double prime $\left(\gamma^{\prime}\right)$, and delta $(\delta)$ phases ${ }^{14)}$. The $\gamma^{\prime}\left(\mathrm{Ni}_{3}(\mathrm{Al}, \mathrm{Ti}, \mathrm{Nb})\right)$ is an ordered face centered $\left(\mathrm{L}_{2}\right)$ structure with a volume fraction of approximately $4 \%^{34)}$. This precipitate has a spherical shape coherent with the matrix $(\gamma)^{1)}$. The primary strengthening phase, $\gamma^{\prime}\left(\mathrm{Ni}_{3} \mathrm{Nb}\right)$, has an ordered body-centered-tetragonal $\left(\mathrm{DO}_{22}\right)$ structure which is metastable and exhibits a slight distortion. The $\gamma$ " also precipitates coherently with the matrix as disks on the $\{100\}$ planes with a volume fraction of about $15-20 \%^{1-4}$. The orthorhombic $\delta\left(\mathrm{Ni}_{3} \mathrm{Nb}\right)$ preferentially nucleates at the grain boundaries and grows along $\{111\}$ planes in the matrix ${ }^{5-6)}$.

Deformation in Alloy 718 occurs by massive planar slip in an heterogeneous fashion ${ }^{4-8)}$. Fournier and Pineau reported that the $\gamma^{\prime \prime}$ precipitates were sheared by dislocations during fatigue cycling and this led to faulting of these particles ${ }^{7)}$. They also reported that deformation twin boundaries were introduced by fatiguing. Fatigue cracks nucleated at the twin deformation bands, and crack initiation occurred only at the late stage of the fatigue lifetime ${ }^{7)}$. In order to establish a lifetime assessment method of Alloy 718, crack initiation stage of the material has to be studied.

The objective of the present study is to establish an effective method of measuring fatigue damage accumulation state of Alloy 718. The intra-grannular distortion analysis (IGD) which has been established to measure creep strains accumulated in $2.25 \mathrm{Cr}-1 \mathrm{Mo}$ steels ${ }^{10,11)}$ is applied to quantify the distortion induced during fatiguing within the grains of Alloy 718 .

\section{Experimental}

Fatigue test bars of $6.35 \mathrm{~mm}$ diameter and gage length $18.5 \mathrm{~mm}$ were machined from an Alloy 718 superalloy disk as used in jet engine turbine disks. The chemical composition, major mechanical properties, and heat treatment histories are summarized in Table I. Fatigue damage was induced in the test bars by strain controlled cycling at two total strain ranges, $\Delta \varepsilon_{\mathrm{t}}=0.8$ and $1.2 \%$ at $400^{\circ} \mathrm{C}$ to the failure $(100 \%$ cumulative fatigue damage, $\mathrm{CD})$, and to the damage factor of $10,30,40$, and $60 \% \mathrm{CD}$ for $\Delta \varepsilon_{\mathrm{t}}=0.8 \%$. Ultimate failure was taken to be the point beyond which the applied stress fell $10 \%$. The tests were performed in a closed-loop electrohydraulic machine under a sinuoidal wave. The frequency of cycling was $30 \mathrm{cycle}$ per minute. The test conditions and results are summarized in Table II.

All of the test bars were cut perpendicular to the stress axis within gage length at least $5 \mathrm{~mm}$ away from major cracks if there were any cracks. The specimens were polished and metallographic observation was made by optical microscopy. Vicker's hardness test was also performed.

Small disks (3 Imm diameter X $0.1 \mathrm{~mm}$ thickness) were made from the $1 \mathrm{~mm}$ thick wafers, and were then electropolished to prepare Transmission Electron Microscopy (TEM) and IGD samples having an approximate thickness of 0.2 to $100 \mathrm{~nm}$. Two types of TEM machines operating at $200 \mathrm{kV}$ were used in this experiment: a Hitachi $\mathrm{H}-700 \mathrm{H}$ to perform the IGD method, a Hitachi HF-2000 to observe microstructural characteristics. Microstructural damage was evaluated by the IGD method and correlated to the cumulative fatigue damage induced in 
Table I Chemical Composition, Mechanical Properties, and Heat Treatments of Inconel 718 Superalloy Used in the Fatigue

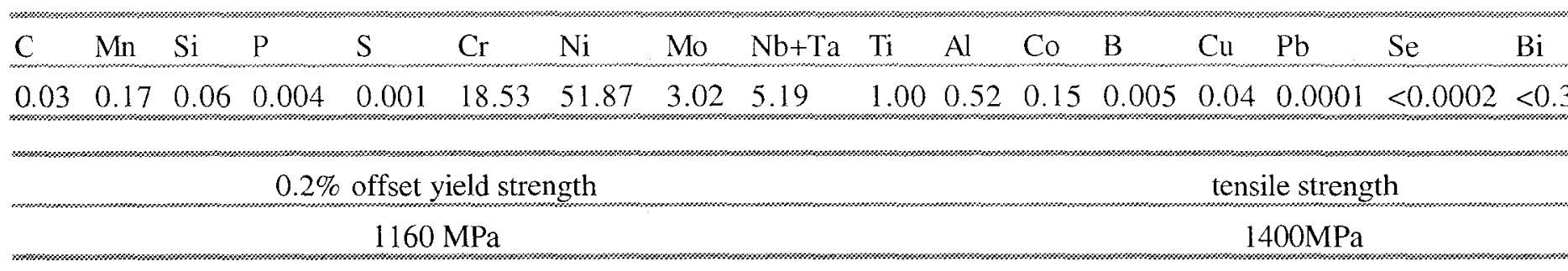

$970^{\circ} \mathrm{C} \times 1$ hour $\rightarrow$ water quench, $718^{\circ} \mathrm{C} \times 8$ hours $\rightarrow 621^{\circ} \mathrm{C} \times 8$ hours $\rightarrow$ air cool (total 18 hours)

8

Table II Fatigue Test Conditions and Results

\begin{tabular}{ccccc} 
Specimen \# & Test Temperature $\left({ }^{\circ} \mathrm{C}\right)$ & Total Strain Range $(\%)$ & Number of Cylcles & Damage factor $(\%)$ \\
IN01 & 400 & 1.2 & 7,830 & 100 \\
IN03 & 400 & 1.0 & 10,428 & 100 \\
IN04 & 400 & 0.8 & 25,700 & 100 \\
IN05 & 400 & 0.8 & 2,570 & 10 \\
IN06 & 400 & 0.8 & 7,830 & 30 \\
IN07 & 400 & 0.8 & 10,428 & 40 \\
IN08 & 400 & 0.8 & 15,420 & 60 \\
As (bulk) & - & - & 0 & 0 \\
As (surface) & - & - & 0 & 0 \\
30 cpm, R=0, sinusoidal wave form & & & surface of th \\
\hline
\end{tabular}


the specimens.

Figure 1 shows the procedure of the IGD method ${ }^{10-11)}$. Kikuchi patterns, generated by a combination of inelastic and elastic scattering of electron beam observed by the TEM is taken from the central part of a grain as a reference point. Then Kikuchi patterns and the TEM photographs of several $(n)$ points around the reference point within the grain are recorded as schematically illustrated in Figure 2. Since Kikuchi patterns represent the crystallographic orientation of the observed area, the average distortion, $\varepsilon_{\mathrm{j}}$, between the measured points and the reference point can be calculated by the following equation:

$$
\varepsilon_{j}=\frac{1}{n} \sum_{i=1}^{n} \frac{\theta_{i}}{d_{i}}
$$

where, $\theta_{i}$ is the angle between the measured point and the reference point, and $d_{i}$ is the distance between the two points. These measurements are repeated for more than five grains and the average distortion is calculated.
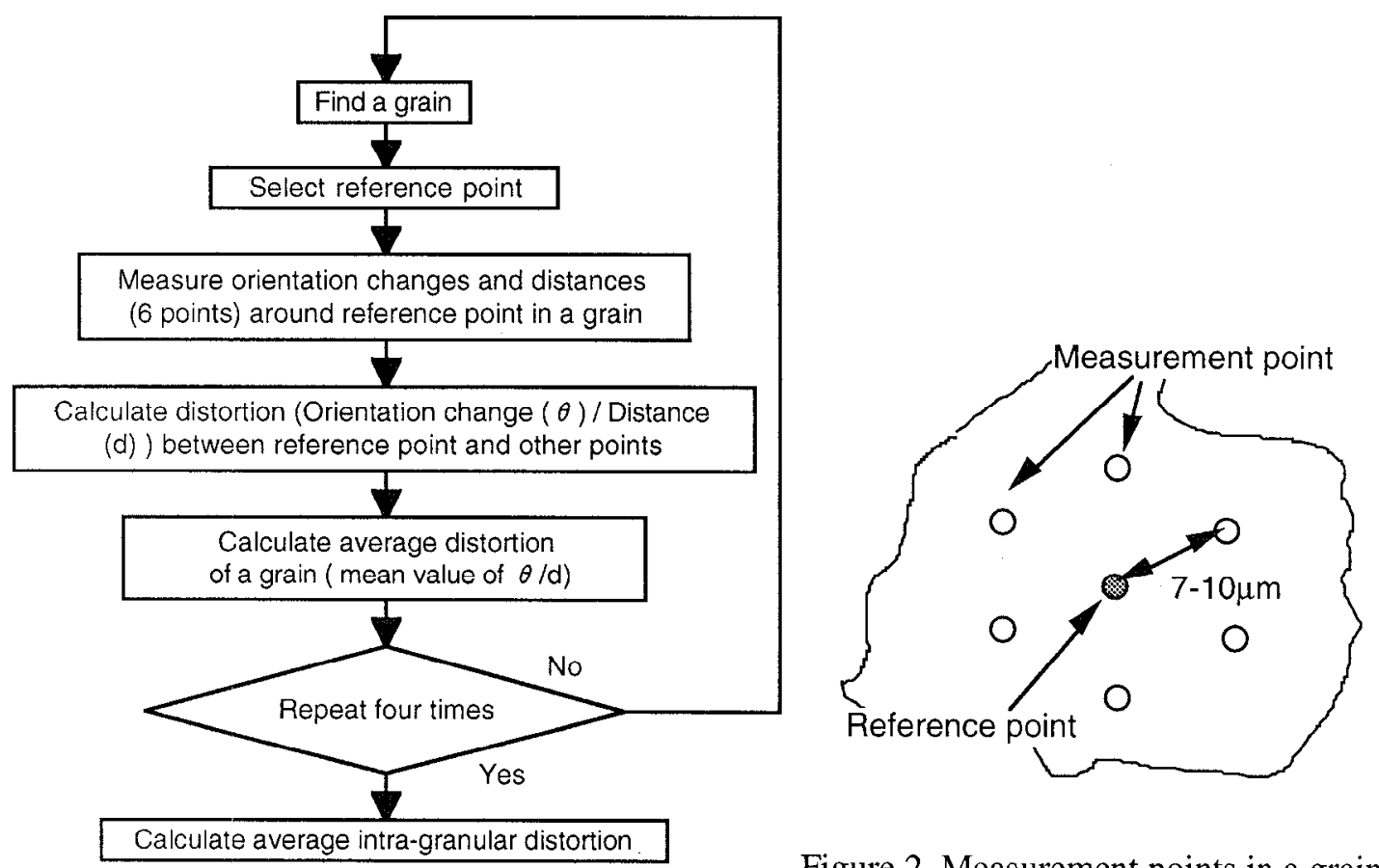

Figure 2 Measurement points in a grain

Figure 1 Measurement of Intra-granular distortion

Figure 3 shows the relationship between the average intra-granular distortion and creep strains in $2.25 \mathrm{Cr}-1 \mathrm{Mo}$ steel ${ }^{9)}$. The IGD measurements are linearly increasing with the increase of creep strains. It is found that the IGD method is effective to measure creep or unidirectional deformation in $2.25 \mathrm{Cr}-1 \mathrm{Mo}$, or stainless steels. In this study, this method is applied to evaluate fatigue damage state in Alloy 718 .

\section{$\underline{\text { Results and Discussion }}$}

The fatigue test conditions in the study and the corresponding results are summarized in Table II. The S-N curve for this material is shown in Figure 4. Fatigue lifetime is slightly longer than previous tests ${ }^{12)}$ since the $\mathrm{R}$ ratios are different. 


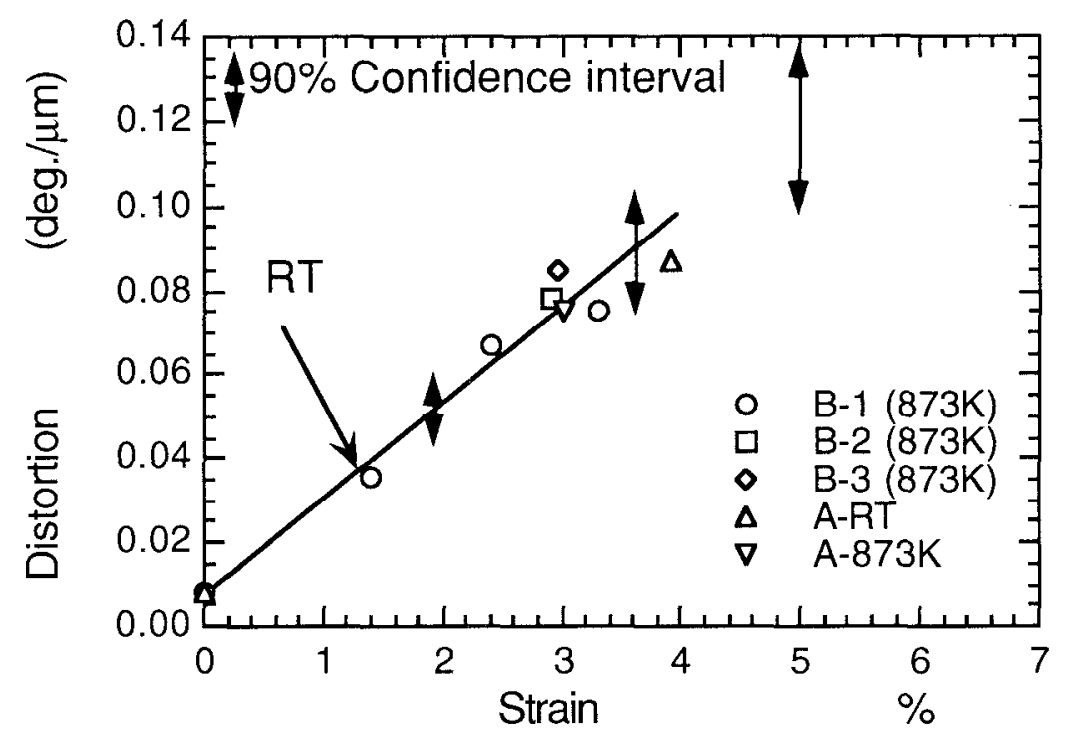

Figure 3 Relation between tensile strain and average distortion of $2.25 \mathrm{Cr}-1 \mathrm{Mo}$ steel

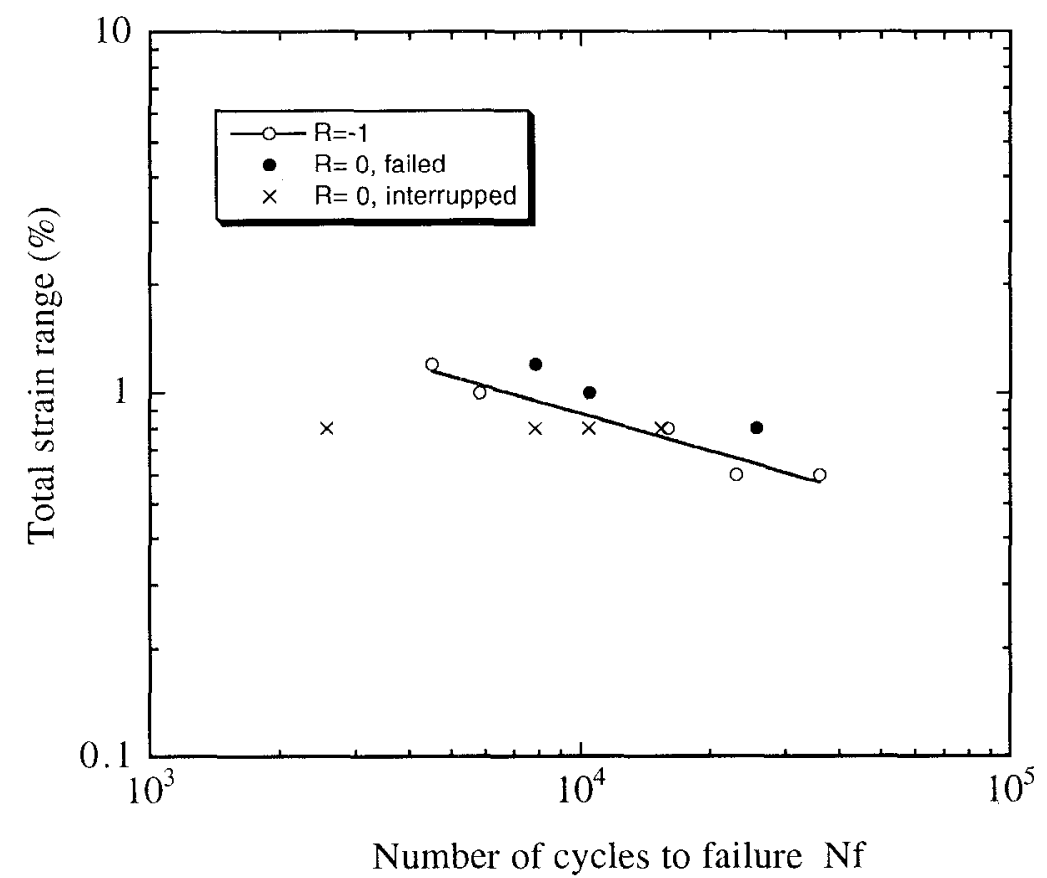

Figure 4 S-N curve for Alloy 718

Optical micrographs of the as received and fatigued samples are shown in Figure 5. Homogeneously distributed globular $\delta$ precipitates are observed in the micrographs. No significant difference is seen in the optical micrographs of fatigued and as-received samples. Hardness test results are shown in Figure 6 . Alloy 718 exhibits slight work-hardening and then softening in the late stage of the fatigue life. 


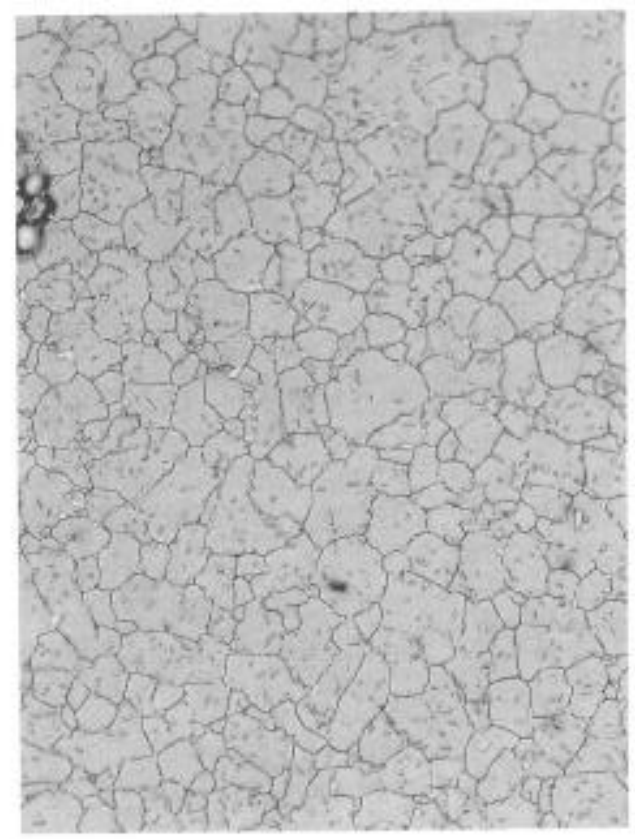

(a) As-received

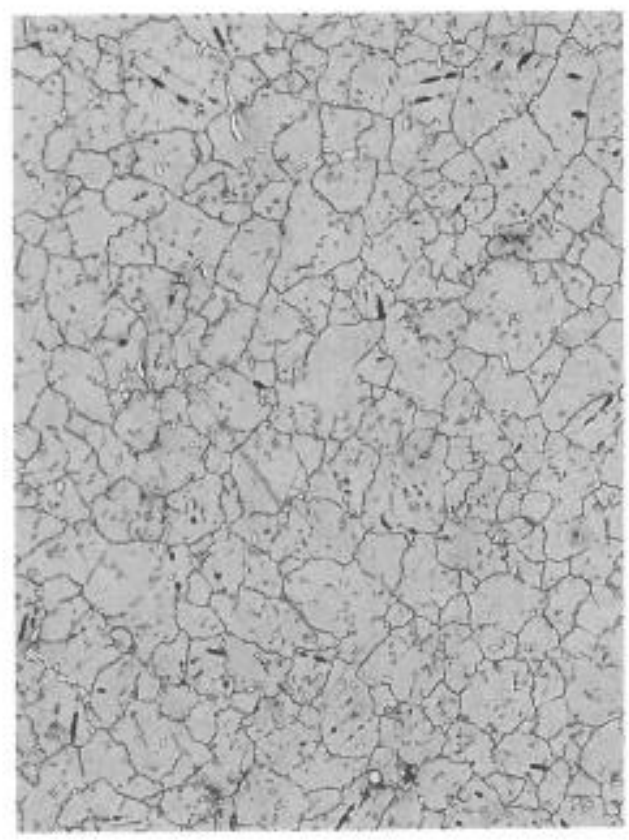

(b) IN01, 100\% CD

$\stackrel{20 \mu \mathrm{m}}{\longmapsto}$

Figure 5 Optical micrographs of as-received and fatigued Alloy 718

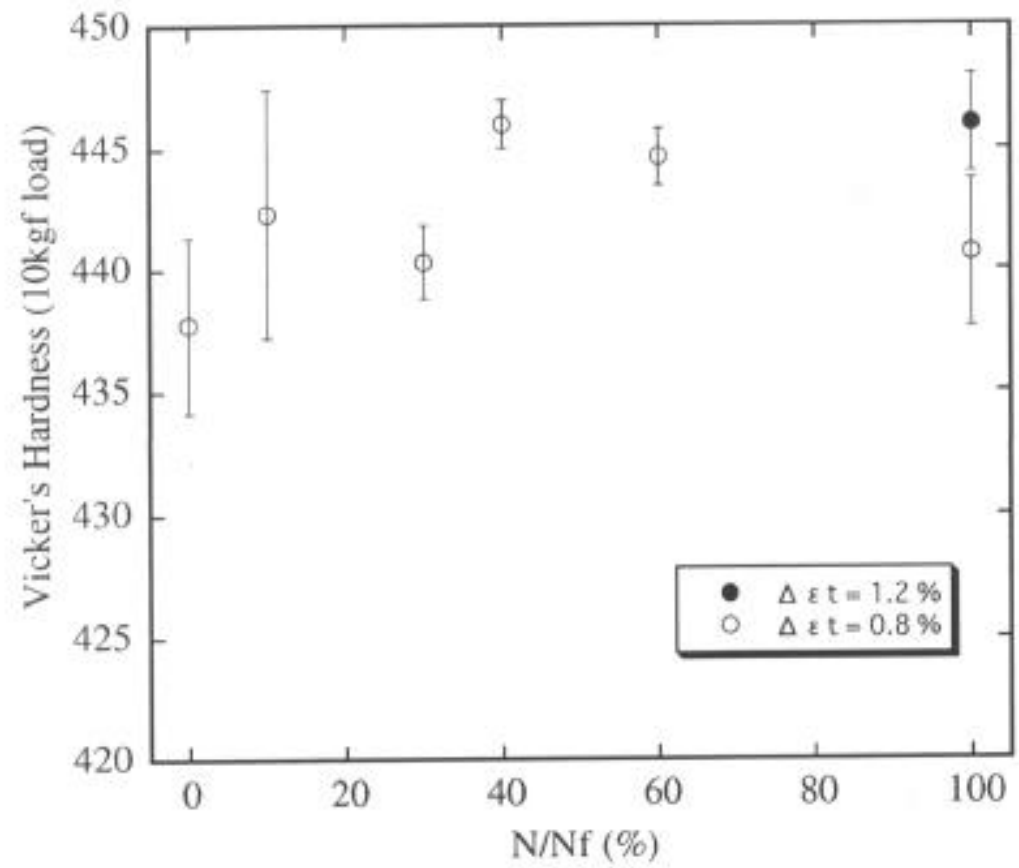

Figure 6 Hardness change of Alloy 718 during fatigue life 
TEM micrographs of the samples are shown in Figure 7. Fine $\gamma$ " precipitates, homogeneously distributed in grains are observed in the TEM micrographs. The TEM micrographs of asreceived and fatigued samples are shown in Figure 7(a) and (b) respectively. It can be seen that many dislocations and planar slip bands are induced by fatigue cycling.

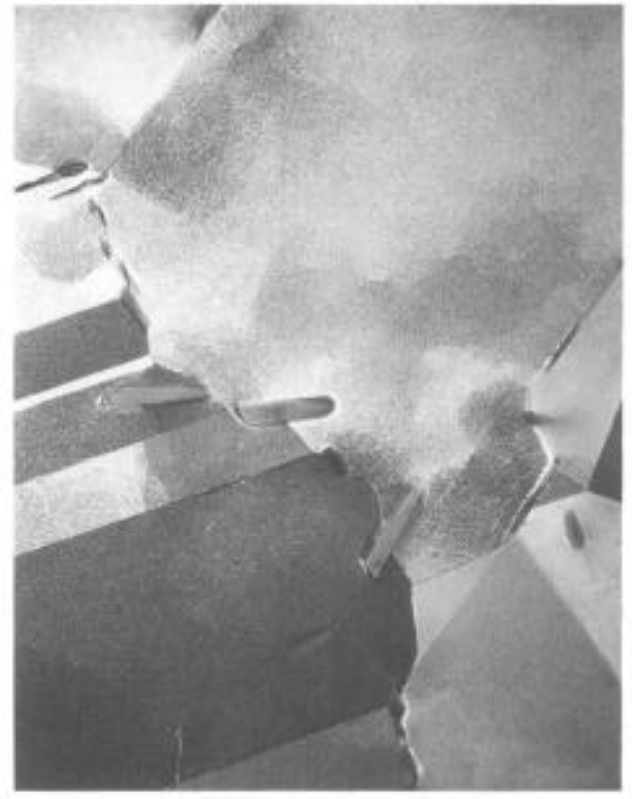

$1.5 \mu \mathrm{m}$

(a) As-received

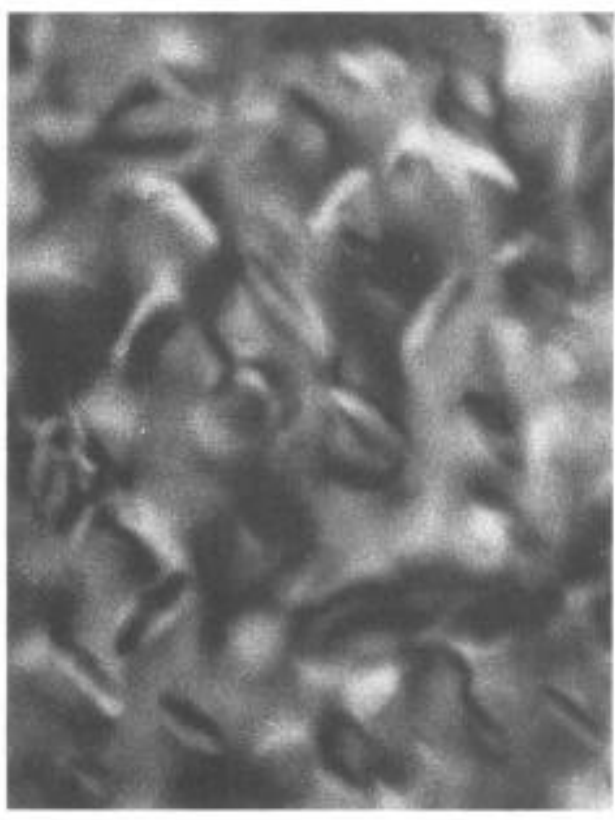

$20 \mathrm{~nm}$

(c) IN01, 100\% CD

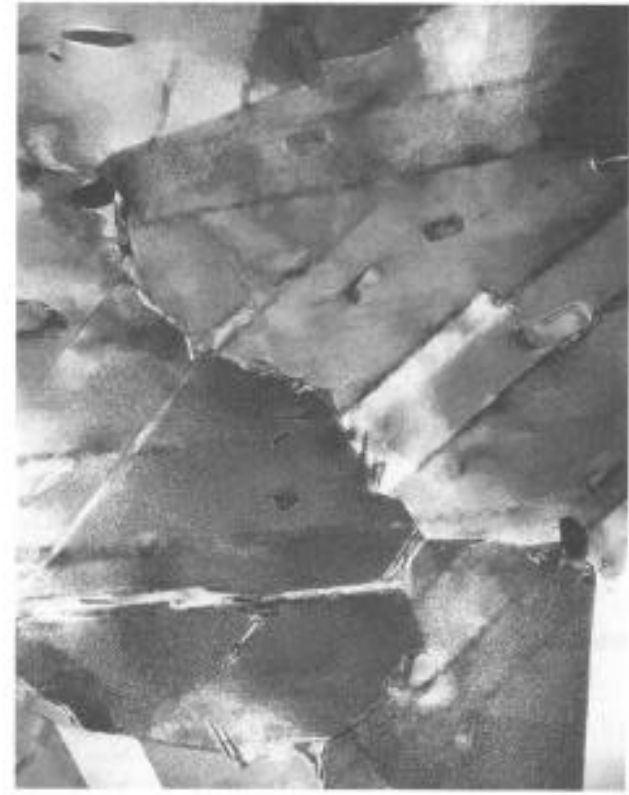

$1.5 \mu \mathrm{m}$

(b) IN01, 100\% CD

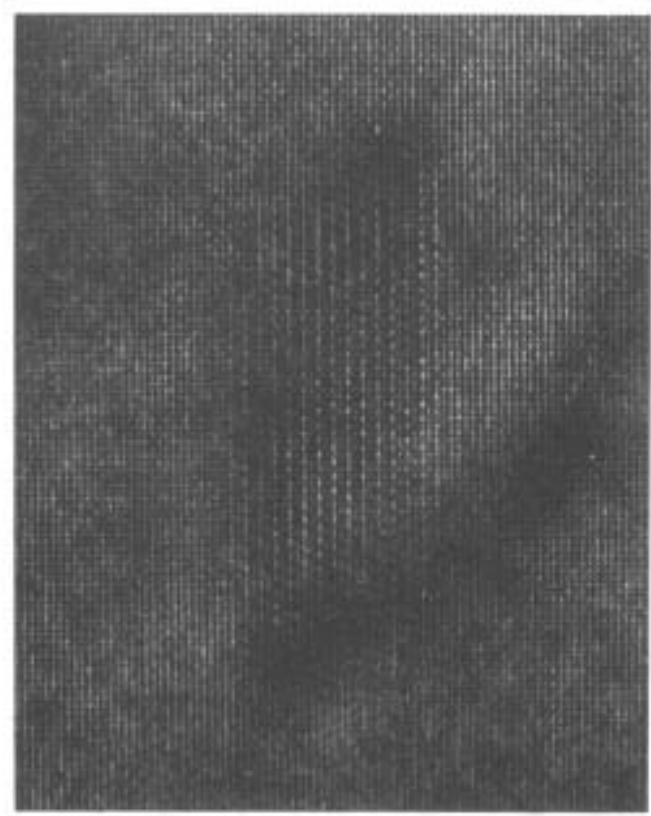

$2.5 \mathrm{~nm}$

(d) IN01, 100\% CD

Figure 7 TEM micrographs of as-received and fatigued Alloy 718 
Substructure formation has been reported in many alloys, such as aluminum ${ }^{13)}$, $\operatorname{copper}^{(3-17)}$, brass $^{14,16)}$ and iron ${ }^{19-21)}$. Typically, dislocation cell stuctures are formed during faliguing due to dislocation interaction from extensive multiple slips. No cell structures, however, are observed in Alloy 718 since the dislocations are restricted to the primary $\{111\}$ slip planes, as cross slip is limited. Although microstructural characteristics such as, dislocation density, planar slip bands, and deformation twin boundaries, are changing during fatigue process, it is not very easy to quantify these changes, because the fine ordered particles dispersed in the material makes the dislocation image vague. In order to quantify the microstructural changes during fatigue accumulation in Alloy 718 , the IGD method is applied.

Figure 8 shows the average intra-granular distortion measured by the IGD method. It can be seen that the IGD measurements are increasing with fatigue accumulation regardless of the total strain ranges of fatigue tests. It should be noted that the IGD measurements of the as-received Alloy 718 samples are larger than that of $2.25 \mathrm{Cr}-1 \mathrm{Mo}^{10-11}$. This is probably because the specimens used in this experiment were taken from a forged disk, and distortions induced by the forging process during fabrication have not been released after the heat treatment.

When a polycrystal material is deformed, each grain deforms on its own slip systems. The material, however, has to maintain compatible deformation at grainboundaries and "geometrically necessary" dislocations are induced as suggested by Ashby". During fatigue process, geometrically necessary dislocations have to be introduced alternating way, but some of them can not be canceled out by to-and-fro motion during fatigue. Thus increase in intragranular distortion during fatiguc in Alloy 718 is less than that of $2.25 \mathrm{Cr}-1 \mathrm{Mo}$ induced by creep or uniaxial strain. It should be interesting to see how much intra-granular distortion would accumulate in this material by unidirectional straining. Comparison between unidirectional deformation and various fatigue test conditions in Alloy 718 is in progress. The IGD analysis has a potential to evaluate fatigue damage accumulation state in Alloy 718. This method can not be a non-destructive evaluation examination at this stage since it requires TEM samples, but the similar analysis could be obtained by the Electron Back Scattering Patterns (EBSP) ${ }^{22)}$ or channeling pattern analysis in the scanning electron microscopy, which may be used as nondestructive analysis.

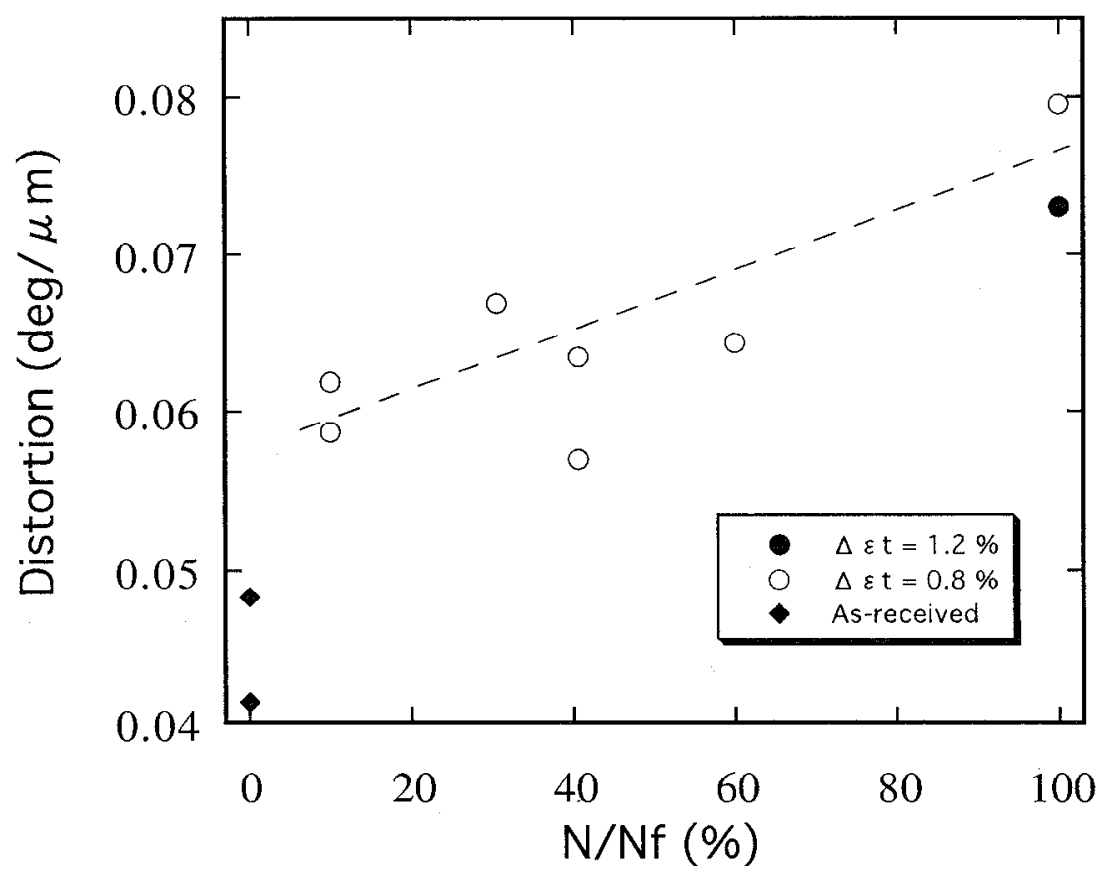

Figure 8 Intragranular distortion change of Alloy 718 during fatigue life 


\section{$\underline{\text { Conclusions }}$}

Fatigue test bars fabricated from an Alloy 718 disk were cyclically deformed at two total strain ranges, $\Delta \varepsilon_{\mathrm{t}}=0.8$ and $1.2 \%$ at $400^{\circ} \mathrm{C}$ to the failure ( $100 \%$ cumulative fatigue damage, $C D$ ), and to the damage factor of $10,30,40$, and $60 \% \mathrm{CD}$ for $\Delta \varepsilon_{\mathrm{t}}=0.8 \%$. These specimens were observed by the optical microscopy and the TEM, and Vicker's hardness tests were also performed. Intra-granular distortion analysis was applied to some of the fatigue induced samples and an as-received sample. The following results were obtained.

1. There is no significant change in the optical micrographs between fatigued and as received samples observed. The sample shows gradual work-hardening followed by softening in the late stage of the fatigue life.

2. Planar slip bands and deformation twins are observed by the TEM in fatigued specimens, but it is difficult to estimate the fatigue damage state only by observation.

3. Intra-granular distortion increases with fatigue damage accumulation. The IGD analysis is effective to measure fatigue damage accumulation state of Alloy 718.

\section{$\underline{\text { References }}$}

1) D.D.Keiser, and H.L.Brown, A review of the physical metallurgy of Alloy 718, ANCR1292, UC-25, February 1976, pp.1-27

2) H.L.Eiseilstein, ASTM, Spec.Tech. Rept., no.369, 1965

3) J.M.Oblak, D.F.Panlonis, and D.S.Duvall, Met. Trans., vol.5, 1974 pp. $143-153$

4) D.F.Panlonis, J.M.Oblak, and D.S.Duvall, Trans. ASM, vol.62, 1969, pp.611-622

5) J.W.Brooks and P.J.Bridges, Metallurgical Stability of Inconel 718, Superalloys 1988, ed. S.Reichman et al., (Warrendale, PA: The Metallurgical Society, 1988) pp.33-42

6) J.F Radavich, The Physical Metallurgy of Cast and Wrought Alloy 718 , Superalloy 718 Metallurgy and Applications, ed. E.A.Loria (Warrendale, PA: The Minerals, Metals \& Materials Society, 1989), pp.229-240

7) S.Kalluri, K.B.S.Rao, G.R.Halford, and M.A.McGaw, Superalloys 718625706 Various Deriv, 1994, pp.593-606

8) D.Fournnier and A.Pineau, Met. Trans. A, vol.8A, 1977, pp.1095-1105

9) M.F.Ashby, Phil. Mag., vol.21, 1970, pp.399-424

10) H. Yoshizawa, M.Nakashiro, S. Kihara, and Y.Nakagawa, PVP-vol.305, 1995, pp. 431436

11) H. Yoshizawa, K.Morishima, M.Nakashiro, S.Kihara, and H.Umaki, Proceedings of the Ninth International Symposium held in Hradec nad Moravici, Czech Republic, 23-26 Sept 1996, pp.164-173

12) IHI unpublished data

13) P. Lukas and L. Kunz, Materials Science and Engineering, vol.62, 1984, pp.149-157

14) S. Karashima, H. Oikawa, and T. Ogura, Trans. JIM, vol.9, 1968, pp.205-213 
15) K. Katagiri, A. Omura, K. Koyanagi, J. Awatani, T. Shiraishi, and H. Kaneshiro, Metall. Trans. A, vol.8A, November 1977, pp.1769-73

16) K. Katagiri, J. Awatani, K. Koyanagi, Y. Onishi, and M. Tsuji, Material Science, October 1980, pp.485-492

17) A.H. Purcell and J. Weertman, Metallurgical Transactions, vol.4, January 1973, pp.349353

18) M. Klesnil and P. Lukas, Philos. Mag. vol.17, 1968, pp.1295-98

19) K. Katagiri, J. Awatani, A. Omura, K. Koyanagi, and T. Shiraishi, Fatigue Mechanisms, Proceedings of an ASTM-NBS-NSF symposium, ASTM STP 675, 1979, pp.106-128

20) J. Awatani, K. Katagiri, and H. Nakai, Metall. Trans. A. vol.9A, January 1978, pp. 111 116

21) T. Ogura, T. Masumoto, and Y. Imlai, Trans. JIM, vol.17, 1976, pp.731-742

22) B.L.Adams, S.I.Wright, and K.Kunze, Met. Trans. A, vol.24, 1993, pp.819-831 